Mutumalion and kovolics in Construcion $\wedge$

G.H. Watson, R.L. Tucker and J.K. Walters (Editors)

(C) 1993 Elsevier Science Publishers B.V. All rights recerned.

\title{
Applications of Large-Scale Manipulators in the Construction Environment
}

\author{
Hsieh, Ting-Ya, Research Assistant \\ Dr. Haas, Carl T., Assistant Professor \\ Department of Civil Engineering \\ University of Texas at Austin \\ Austin, Texas 78712, USA
}

\begin{abstract}
Large-Scale Manipulators (LSMs) are gaining attention in construction automation research because of their long reach and positioning capabilities. A case study based on the Model Plant data compiled by the Construction Industry Institute indicates that LSMs have very high potential in industrial construction. They can be used for pipe, cable tray and structural steel erection as well as elevated concrete placement, painting and sandblasting, which on average constitute $33 \%$ of the total project work-hours. Use of LSMs can reduce the amount of non-value added tasks, increase productivity, shorten construction time, and improve workers' safety. A task selection framework which uses a decision matrix to evaluate the uses of LSMs is developed. The same framework could also be used for evaluating the usefulness of other types of automated equipment or machinery in various construction projects.
\end{abstract}

\section{INTRODUCTION}

Historically, large-scale manipulators (LSMs) have been of major interest in construction automation and robotics. The most promising capability of LSMs is in independently and quickly positioning and orienting special tooling, inspection devices, concrete pump hoses, and construction materials in a large 3-D space. Despite significant developments world wide, a comprehensive study of LSMs' potential applications still does not exist. Many existing LSMs are designed for only one application and their limited utility in the construction environment may render them uneconomical particularly due to the high initial costs.

Therefore, maximizing the use of LSMs in construction is a critical step forward achieving a high profitability, and as this paper illustrates, maximizing the use of LSMs is best achieved by examining their potential applications during the design stage. The purpose of this paper is to present a method for identifying suitable applications of LSMs in construction. A task selection procedure to systematically pinpoint the applications of LSMs on a project basis is developed. Based on a case study, this framework is implemented for a petrochemical construction project to demonstrate some of the potential applications of LSMs. While the scope of this study is limited to petrochemical construction projects, more LSM applications exist in other types of projects such as commercial construction and highway construction.

\section{CONSTRUCTION MANIPULATORS}

Due to structure and complexity differences in the production processes from industry to industry, the definition of manipulators varies. In manufacturing where most operations are repetitive and can be performed with very few variations, and where the working environment is often well structured, manipulators are defined as machinery that are re-programmable and assisted with some sensor guidance in order to move materials, parts, tools or specialized devices through various fixed paths with high accuracy and at high speed. In military and aerospace, their definition changes to machinery which perform non-repetitive tasks in an unknown and often ill-structured environment with good accuracy, therefore, these manipulators often have to be equipped with a highly complex sensory system, a sophisticated mobility system, and learning capabilities. 
Construction shows some characteristics of both areas. Often, its environment is ill-structured and complex. Tasks are relatively repetitive but can seldom be performed without changes in terms of process, material and dimension. The source of errors are numerous with an accumulative nature. However, precision requirements are normally not as critical as those in manufacturing. Given these conditions, construction manipulators may be described as machinery which bear the following characteristics:

- Large force capability

- Often hydraulically powered

- With many (sometimes more than six) degrees of freedom

- With human involvement in the control loop (man-machine interface)

- Usually with computer and sensor control assistance

To further define construction manipulators, it is useful to generalize the construction environment into an internal environment (inside the building envelope) and an external environment (outside the building envelope) [1]. In the internal environment where the work space is relatively small and confined, construction manipulators are used to assemble partitions and fixtures, and finish interior walls and ceiling. In the external environment where the work space is open and large, construction manipulators are applied to erect large bore ripes and steel beams, and finish exterior building closure. The two groups of manipulators are dissimilar mainly due to three parameters imposed by the environment as well as the tasks which they perform: (1) the reach, (2) the payload and (3) the mobility.

The focus of this paper is on the latter group of construction manipulators which are used in the external environment. They are called large-scale manipulators (LSMs) in this paper as opposed to smallerscale manipulators used in the internal environment. Due to different environment characteristics and task requirements, LSMs impose rather distinct considerations in component design such as the manipulation/actuating system, the end effector, the motion system, the sensory system, and the control system [2]. Consequently, the core technology required by LSMs differs largely from that in industrial and smallerscale construction manipulators. Further discussion of the core technology is outside the scope of this paper.

\section{TASK SELECTION FRAMEWORK}

To identify the potential applications of LSMs, a task selection procedure is proposed. This procedure is also applicable to opportunity identification of other automated construction systems on a project basis, and it involves seven steps, described as follows:

\section{Machine Capability Identification}

Generally, the potential of an automated system for construction applications is determined by how well it can satisfy the needs or concerns of construction tasks under four categories: safety, productivity, quality, and human factors ${ }^{1}$ [3]. Therefore, a machine's capability can be expressed in terms of the task concerns which it can satisfy. The task concerns that can be used to describe a machine's capabilities are identified in Table 1.

\section{Project Selection}

The essential project data to implement this procedure include a complete construction task list, labor costs, and other construction-related costs such as supportive material costs. The selection of project type normally depends not on the interest of researchers but the needs of potential users of the system. To collect useful data, the selected project should possess the following qualities:

- representative of its type

- comprising a considerable volume of the construction industry

- exhibiting needs for technological advancements

- feasible to obtain project data 
Table 1 Task Concern Checklist

\begin{tabular}{|c|c|}
\hline A. Safety & C. Quality \\
\hline $\begin{array}{l}\text { A1. Eliminate work that is hazardous to health } \\
\text { - breathing problems } \\
\text { - mental problems } \\
\text { - vision problems } \\
\text { - hearing problems } \\
\text { - long-lasting back bending } \\
\text { A2. Eliminate physically dangerous work } \\
\text { - falling more than six feet } \\
\text { - falling less than six feet } \\
\text { - extreme temperatures } \\
\text { - high electrical voltage or current } \\
\text { - struck by material or tools } \\
\text { - dangerous machinery operation } \\
\text { - dangerous hand tool operation }\end{array}$ & $\begin{array}{l}\text { C1. Reduce rework due to errors and omissions } \\
\text { - low repeatability } \\
\text { - low accuracy } \\
\text { - difficult to measure outcome } \\
\text { C2. Increase precision of installation } \\
\text { - high accuracy } \\
\text { - high consistency/repeatability }\end{array}$ \\
\hline B. Productivity & D. Human Factors \\
\hline $\begin{array}{l}\text { B1. Eliminate physical constraints to productivity } \\
\text { - congested work space } \\
\text { - coordination among many trades } \\
\text { - meticulous connections and fixtures } \\
\text { - slow operation required by safety } \\
\text { B2. Eliminate cognitive constraints to productivity } \\
\text { - large amount of computation } \\
\text { - high memory requirement } \\
\text { - waiting for information } \\
\text { - decision making required } \\
\text { - trial-and-error process involved } \\
\text { B3. Eliminate non-value added process } \\
\text { - overhead and planning effort } \\
\text { - preparation work } \\
\text { - supportive work } \\
\text { - time-consuming safety procedures } \\
\text { B4. Improve efficiency of repetitive work } \\
\text { - faster completion of repetitive processes } \\
\text { - combination of processes }\end{array}$ & $\begin{array}{l}\text { D1. Reduce need for specialized skills in shortage } \\
\text { • skills difficult to train } \\
\text { • general shortage of labor } \\
\text { D2. Eliminate unfavorable work } \\
\text { • dirty work } \\
\text { - unpleasant work } \\
\text { D3. Eliminate boring work } \\
\text { • low to no skill required } \\
\text { - routine work in isolation } \\
\text { D4. Eliminate physically exhaustive work } \\
\text { - heavy handling } \\
\text { - tiring body posture } \\
\text { - wearing heavy safety equipment }\end{array}$ \\
\hline
\end{tabular}

\section{Machine Potential Evaluation}

To determine the potential of an automated system in a particular project, the machine's capabilities identified in Step 1 are compared with the project tasks obtained in Step 2. A convenient way to conduct this evaluation is by using a tabular form in which all project task are listed in the far left column and the machine capabilities in the top row. In this fashion, the value to be assigned to each blank depends on whether a machine's capability meets the concern of a particular task. If the machine's capability can satisfy the concern of a task, the respective blank is marked, otherwise it is left intact 2 . The total number of marks that are given for each project task is then added up, showing the preliminary ranking. After completing the evaluation for all project tasks, a ranked list that shows all project tasks with their concern rating can be generated.

\section{Task Volume Calculation}

In this step, the project tasks that show low or no potential in gaining benefits from using the automated system are eliminated from the ranked list. Then, the lask volumes of the remaining tasks in the ranked list are calculated. A task volume is defined as the construction-related portion of a project assignable to a particular task. Construction costs, consisting of mainly labor costs and equipment costs, are a good indication of the volume of a task. Material costs being relatively independent of the construction portion of a project are not included within the definition of a task volume. 
Accordingly, a task volume is large when completing this task requires much labor (e.g. high labor costs) and/or a high level of mechanized power (e.g. high equipment cost.s). Because equipment costs are normally comparatively insignificant to labor costs, the labor requirement or the percentage of total project work-hours of a task can well represent a task volume.

\section{Decision Matrix Development}

Up to this point, two sets of information related to project tasks have been derived. The first set is obtained by evaluating each project task with respect to the machine capabilities. In the evaluation, a project task receives a mark if one of the machine capabilities meets one of its concerns. A second set of information is associated with the task volume. A task volume is large when it requires much labor, and the labor requirement is represented by the percentage of total project work-hours.

Based on the two sets of information, a decision matrix (Figure 1) can be developed. The number of task concerns and task volume by percentage of total project work-hours are each represented by an axis. Each project task is marked on the matrix as a point and is positioned according to its values on both axes.

\section{Task Ranking}

Once the decision matrix is developed, the next step is to decide the ranking or priority among the project tasks shown as points in the matrix. Since accuracy in this framework is not critical, there is little sense to reckon the priority for every project task. Rather, it is more convenient to divide the decision matrix into several regions and determine the priority of each region. From experience, four to five divisions are appropriate for comparison. In dividing the decision matrix, a simple distance principle can be followed (Figure 1).

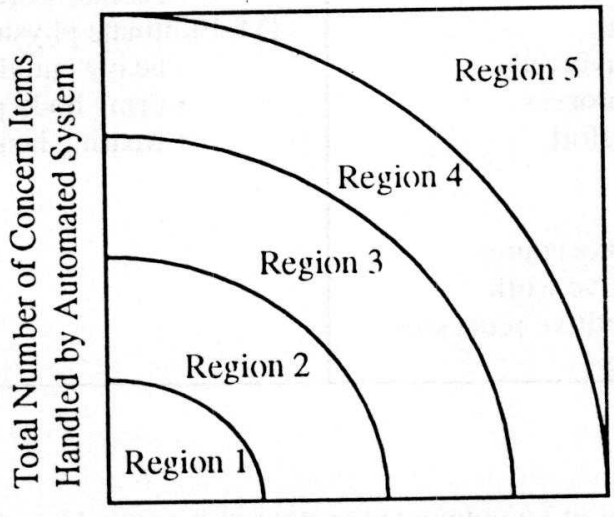

\% of Total Project Work-Hours

Figure 1 Division Principles of the Decision Matrix

When the two dimensions of the decision matrix are considered to possess the same weight or the relative importance between them is difficult to establish, the distance principle can be used. In this principle, the priority of each region in the matrix is determined by its distance from the origin or the botiom left comer of the matrix. Consequently, Region 2 receives a higher priority than Region 1 but a lower priority than Region 3.

\section{Potential Evaluation}

One can easily examine from the decision matrix the potential of an automated system by aggregating the total project work-hours of the tasks that appear in the high-priority regions. A further step is to divide these high-priority tasks under major activity categories before aggregating their work-hours. Since construction activities may have temporal (sequential or parallel) relationships and can be similar in terms of constructing methods, this approach will provide insight for the economic analysis of the actual system implementation. 


\section{CASE STUDY}

In this example, the University of Texas Large-Scale Mamipulator (UT LSM) is chosen for evaluation. The UT LSM can be described physically as a computer controlled, electro-hydraulically actuated, duel functional, material handling device attached to the boon nose of a 22-ton, telescopic, rough-terrain crane.

According to the system's characteristics [4], its capabilities are expressed in terms of the task concerns listed in Table 1 and summarized as follows:

A1. to eliminate work which is hazardous to health

- breathing problems

- vision problems

- hearing problems

- long-lasting back bending

A2. to eliminate physically dangerous work

- falling more than 6 feet

- extreme temperatures

- high electrical voltage/current

- dangerous machine operation

- dangerous hand tool operation

B3. to eliminate non-value added construction processes

- supportive work

- time-consuming safety procedures

B4. to improve the efficiency of repetitive construction processes

- faster completion of repetitive construction processes

- combination of processes

D4. to eliminate physically exhaustive work

- heavy handling

- tiring body posture

- wearing heavy safety equipment

The Construction Industry Institute (CII) Model Plant is a baseline against which to measure construction productivity. A typical petrochemical facility was chosen as the physical baseline facility. CII members (contractors and owners), based on their own actual experience, have estimated the amount of construction labor that would be required to build selected parts of the Model Plant utilizing a code of accounts which has been established for the various scones of work at both a detailed and summary level. The Model Plant data used in this case study are averaged over nine bidder's estimates. In short, this petrochemical project has sixteen categories of activities which contain a total of 121 tasks. Further information regarding the project tasks are not provided in this paper but can be found in CII publications $[5,6]$.

The 121 project tasks under sixteen categories are evaluated against the sixteen machine capabilities listed above under four main categories. In this study, two senior engineers, whose combined expertise in petrochemical construction exceeds seventy years, were asked to perform the evaluation in two separate sessions.

Based on the CII Model Plant data, the work-hours of each project task are calculated. Due to length limitation, only partial results of the machine capability evaluation and the task volume calculation are shown in Table 2. Fifty-seven out of the 121 project tasks have at least one task concern item, representing more than $50 \%$ of total project work-hours. The project tasks which show no potential have been eliminated from the original ranked list.

Based on Table 2, the decision matrix containing the task concern dimension and the task volume dimension can be developed. Using the distance division principles, the decision matrix is presented in Figure 2. To maintain neatness of presentation, only the distinguishable points are accompanied with the respective task number. 
Table 2 Summary of Ranked List (After Excluding "No Potential" Tasks)

\begin{tabular}{|c|c|c|c|c|c|c|c|c|c|}
\hline $\begin{array}{l}\text { Task } \\
\text { No. } \\
\end{array}$ & Project Tasks & Concerns & $\begin{array}{c}\% \text { of } \\
\text { Total WH } \\
\end{array}$ & Total WH & $\begin{array}{l}\text { Task } \\
\text { No. }\end{array}$ & Project Tasks & Concerns & $\begin{array}{c}\text { \% of } \\
\text { Total WH }\end{array}$ & Total WH \\
\hline \multicolumn{5}{|c|}{ 01. Site Preparation } & \multicolumn{5}{|c|}{ 15. Building Construction } \\
\hline 0130 & Site Cut and Fill & 1 & $0.82 \%$ & 4206 & 1511 & Exterior Walls \& Roof & 4 & $0.01 \%$ & 38 \\
\hline 0140 & Demolition Existing Structures & 8 & $0.01 \%$ & 65 & 1521 & Foundations & 3 & $0.20 \%$ & 1021 \\
\hline \multicolumn{5}{|c|}{ 02. Site Improvements } & \multicolumn{5}{|c|}{ 16. Aboveground Racked Piping } \\
\hline 0212 & Placement of Culverts & 4 & $0.08 \%$ & 398 & 1631 & Spool Erection- $<=2 "$ & 7 & $0.75 \%$ & 3817 \\
\hline 0250 & Fencing & 1 & $0.07 \%$ & 380 & 1632 & Sprool Erection- 2.5" - 12" & 7 & $3.84 \%$ & 19624 \\
\hline \multicolumn{5}{|c|}{ 03. U/G Electrical } & 1633 & Spool Erection- > = 14" & 7 & $0.42 \%$ & 2173 \\
\hline 0320 & Direct Burial Cable & 2 & $0.47 \%$ & 2417 & 1636 & Field Run Pipe $>2 "$ & 2 & $2.03 \%$ & 10382 \\
\hline 0330 & Underground Conduit/Duct & 3 & $2.99 \%$ & 15292 & 1637 & Hangers and Supports & 7 & $0.40 \%$ & 2050 \\
\hline \multicolumn{5}{|c|}{ 04. U/G Piping } & 1638 & Testing, X-Ray, Cleaning, etc. & 7 & $0.09 \%$ & 468 \\
\hline 0411 & Pressure Flow < 12" & 5 & $3.86 \%$ & 19757 & 1696 & Piping Material Handling & 5 & $0.22 \%$ & 1143 \\
\hline 0412 & Pressure Flow 12" - 30" & 4 & $1.34 \%$ & 6851 & 1697 & Scaffolding & 6 & $0.65 \%$ & 3304 \\
\hline 0421 & Gravity Flow < 12" & 5 & $0.09 \%$ & 470 & \multicolumn{5}{|c|}{ 17. Aboveground Non-Rack Piping } \\
\hline \multicolumn{5}{|c|}{ 08. Concrete } & 1735 & Field Run Pipe- $<=2$ " Erection & 1 & $1.48 \%$ & 7559 \\
\hline 0812 & Foundations $3-50 \mathrm{CY}$ & 3 & $1.67 \%$ & 8558 & 1737 & Hangers and Supports Erection & 7 & $1.28 \%$ & 6559 \\
\hline 0813 & Foundations $>50 \mathrm{CY}$ & 3 & $4.34 \%$ & 22189 & 1738 & Testing, X-Ray, Cleaning, etc. & 7 & $1.05 \%$ & 5392 \\
\hline 0814 & Special Slabs on Grade & 4 & $0.17 \%$ & 875 & 1796 & Piping Material Handling & 5 & $0.76 \%$ & 3899 \\
\hline 0840 & Elevated Structures \& Slabs & 7 & $0.35 \%$ & 1769 & 1797 & Scaffolding & 6 & $0.67 \%$ & 3404 \\
\hline 0850 & Structures Poured in Place & 3 & $0.03 \%$ & 174 & \multicolumn{5}{|c|}{ 18. Aboveground Electrical } \\
\hline 0860 & Walled Structures \& Supports & 6 & $5.43 \%$ & 27770 & 1821 & Aboveground Conduit & 7 & $2.87 \%$ & 14708 \\
\hline 0870 & Drilled Footings & 3 & $0.03 \%$ & 150 & 1822 & Cable Tray Systems & 7 & $0.47 \%$ & 2406 \\
\hline \multicolumn{5}{|c|}{ 09. Specialized Concrete } & 1831 & Wire/Cable in Tray/Conduit & 7 & $2.89 \%$ & 14781 \\
\hline 0910 & Grout & 3 & $0.57 \%$ & 2917 & 1872 & Poles/Towers/Guys/Anchors & 4 & $0.27 \%$ & 1383 \\
\hline 0911 & Poured Fireproofing & 4 & $0.69 \%$ & 3511 & 1873 & Area/Strut Lighting Poles & 4 & $0.02 \%$ & 89 \\
\hline \multicolumn{5}{|c|}{ 12. Structural Steel } & 1877 & Feed Rail- Trolley Buss & 5 & $0.08 \%$ & 425 \\
\hline 1212 & Steel Erection (Light) & 8 & $0.12 \%$ & 602 & 1897 & Scaffolding & 6 & $0.08 \%$ & 387 \\
\hline 1214 & Steel Erection (Medium) & 8 & $0.10 \%$ & 531 & \multicolumn{5}{|c|}{ 19. Instrumentation } \\
\hline 1216 & Steel Erection (Heavy) & 8 & $0.42 \%$ & 2171 & 1921 & Instrument Conduit System & 7 & $0.23 \%$ & 1188 \\
\hline 1222 & Misc. Support Erection & 7 & $0.14 \%$ & 741 & 1922 & Instrument Cable tray System & 7 & $0.05 \%$ & 246 \\
\hline 1242 & Erection - Handrails & 8 & $0.05 \%$ & 272 & 1931 & Instrument Piping & 7 & $0.26 \%$ & 1305 \\
\hline 1244 & Erection - Ladders & 8 & $0.03 \%$ & 169 & 1941 & Install Panels \& Racks & 6 & $0.01 \%$ & 65 \\
\hline 1247 & Erection - Stairs & 8 & $0.03 \%$ & 164 & \multicolumn{2}{|c|}{ 21. Painting } & & & \\
\hline 1248 & Grating & 8 & $0.15 \%$ & 751 & 2111 & Paint Structural Steel & 7 & $0.02 \%$ & 100 \\
\hline \multirow[t]{3}{*}{1252} & Pipe Racks Erection & 8 & $2.41 \%$ & 12352 & 2112 & Paint Pipes & 8 & $0.04 \%$ & 188 \\
\hline & & & & & 2113 & Paint Equipment & 7 & $2.75 \%$ & 14067 \\
\hline & & & & & 2120 & Special Coatings & 7 & $1.19 \%$ & 6078 \\
\hline
\end{tabular}




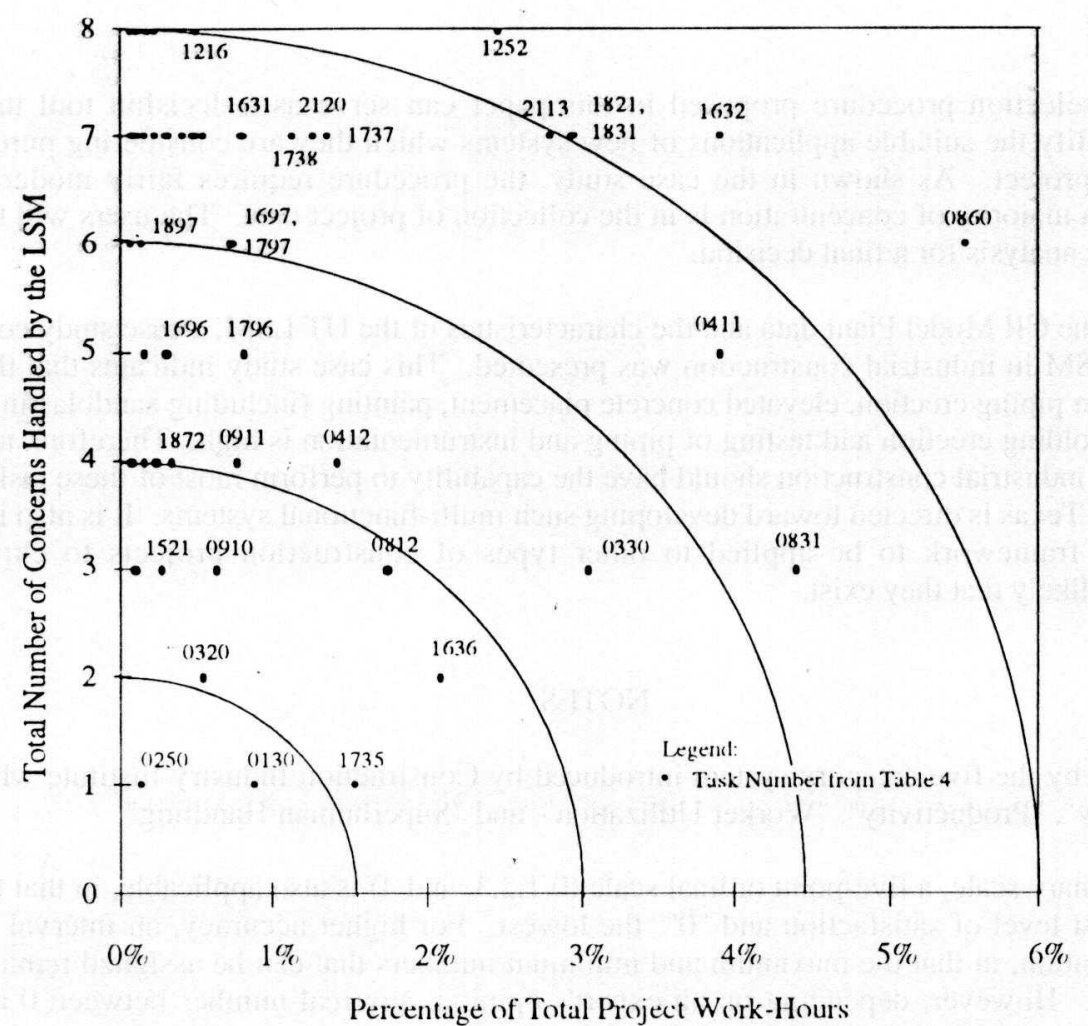

Figure 2 Decision Matrix Using the Absolute Division Principle

From Figure 2, some observations regarding the ranking of potential applications of the UT LSM can be summarized:

(1) Tasks which exhibit very high potential for LSM applications are "Aboveground Racked Piping Spool Erection from 2.5" to 12" in Pipe Diameter", "Concrete Placement for Walled Structures and Supports", "Pipe Rack Erection", "Painting Pipes", "Aboveground Conduit and Cabie Tray Erection", and "Underground Pressure Flow Piping, Less Than 12" in Pipe Diameter".

(2) "Underground Conduit and Duct Erection" and "Concrete Placement in Foundations Larger Than 50 Cubic Yards" represent two applications that have high task volumes and low concern ratings.

(3) A large concentration of project tasks in the top-left corner may indicate high potential for LSM application but lack attractive profitability individually. These tasks generally center in the following major areas:

- Structural Steel Erection

- Aboveground Piping Erection

- Aboveground Non-Racked Piping Erection

- Instrumentation

(4) $\mathrm{By}$ combining the volumes of the project tasks identified in Items (1), (2) and (3), the potential of the UT LSM in petrochemical construction is very high:

- Piping Erection

- Elevated Concrete Placement

- Painting (Including Sandblasting)

- Structural Steel Erection

- Scaffolding Erection

- Testing, X-Ray, Cleaning, etc

- Demolition
$17.33 \%$

$5.77 \%$

$3.99 \%$

$3.47 \%$

$1.39 \%$

$1.15 \%$

$0.01 \%$ 


\section{CONCLUSICNS}

The task selection procedure proposed in this paper can serve as a decision tool that will help potential users identify the suitable applications of new systems which they are considering purchasing for a particular type of project. As shown in the case study, the procedure requires fairly moderate effort to implement, in that a majority of concentration is in the collection of project data. The users will then perform their own economic analysis for a final decision.

Based on the CII Model Plant data and the characteristics of the UT LSM, a case study concerning the applications of a LSM in industrial construction was presented. This case study indicates that the combined potential of LSMs in piping erection, elevated concrete placement, painting (including sandblasting), structural steel erection, scaffolding erection and testing of piping and instrumentation is high. Therefore, an ideal LSM that is designed for industrial construction should have the capability to perform most of these tasks. Research at the University of Texas is directed toward developing such multi-functional systems. It is also important for the task selection framework to be applied to other types of construction projects to explore further opportunities. It is likely that they exist.

\section{NOTES}

1. This is modified by the five-category system introduced by Construction Industry Institute which includes "Safety", "Quality", "Productivity", "Worker Utilization", and "Superhuman Handling".

2. In stead of the binary scale, a five-point ordinal scale (0,1,2,3, and 4) is also applicable, in that the value "4" means the highest level of satisfaction and "()" the lowest. For higher accuracy, an interval scale can be used in the evaluation, in that the maximum and minimum numbers that can be assigned remain at "1" and " 0 ", respectively. However, depending on an expert's opinion, any real number between 0 and 1 can be given to represent the level of satisfaction.

\section{REFERENCES}

1. Warszawski, A., and Sangrey, D A. (1985). "Robotics in Building Construction.", Journal of Construction Engineering and Management, ASCE, 111(3), 260)-280.

2. Paul, R. P. (1982). "Robot Manipulators: Mathematics, Programming and Control." MIT Press, Cambridge.

3. Tucker, R. L. (1982). "Construction Technology Needs and Priorities." Report to the Business Roundtable, University of Texas at Austin, April.

4. Fisher, D. J. (1989). "Piping Erection Constructability Issues in a Semi-Automated Environment." Dissertation, University of Texas at Austin. May.

5. Construction Industry Institute (1986). Model Plant, Publication 2-1, Austin, Texas, October.

6. Construction Industry Institute (1988)., Model Plant Update, Publication 2-2, Austin, Texas ${ }_{2}$ November. 